\title{
Exploration and Application in Teaching Integrated Circuits Based on CDIO
}

\author{
Zhang Lei ${ }^{1, a}$, Li Xiangnan ${ }^{2, b}$, Wang Xinghua ${ }^{3, c}$ \\ ${ }^{1,2,3} 5$ South Zhongguancun Street, Haidian District, Beijing Institute of Technology, China \\ azhl666@bit.edu.cn, 'Ixn196768@163.com, '89811@bit.edu.cn
}

\section{Key words: CDIO; Experiment teaching; Teaching reform}

\begin{abstract}
The CDIO engineering education model is the latest achievement in international engineering education reforms. This engineering practice and knowledge structure is dependent on the organic connection that allows students to actively participate in courses, thus fully mobilizing students' enthusiasm and creativity. This article mainly elaborates on the CDIO education model and also discusses its problems and possible solutions.
\end{abstract}

\section{Introduction}

Conceive, Design, Implement, Operate (CDIO) is an education initiative pioneer. Engineering education based on the new education model of CDIO includes design-and-build projects, demonstrates the interdisciplinary nature of engineering, and stresses engineering fundamentals within the context of the actual process that engineers use. Since 2000, four universities such as the Massachusetts Institute of Technology and the Swedish Royal Institute of Technology University have focused on the multinational research project, with nearly $\$ 20$ million in funding from the Knut and Alice Wallenberg Foundation. After four years of exploration and research, they founded the CDIO engineering education concept and established the international cooperation organization named CDIO [1-3]. By 2008, more than 20 universities from Denmark, Finland, France, South Africa, Singapore, China and several other countries joined the CDIO cooperation organization to make a joint effort to develop and perfect the CDIO teaching model [4]. In 2005, several universities in China introduced the concept of CDIO in teaching. The Ministry of Education himself organized the CDIO engineering education model pilot work. At present there are mechanical, electrical, agriculture and forestry, medical and various other majors in nearly one hundred colleges that carry out the CDIO teaching model. The CDIO engineering education model has produced positive results in the many fields of engineering education in China.

\section{The notion of the experiment teaching reform based on CDIO model}

Engineering in the real world requires more than knowledge of engineering fundamentals; it requires abilities ranging from experience with hands-on design-build projects to skills in communications and teamwork. An engineering program formed within the framework of CDIO teaches professional engineering foundation knowledge, personal skills, and interpersonal skills from working in teams in integration, as would happen for engineers working in the field [5].

Through the CDIO model of experimental teaching, students are enabled to master conception, design, implementation, and the whole process of operation for a real-word electrical product. The CDIO model also provides chances for students to experience the engineering practice in real time, as their professors present their research in tandem with their regular lectures. Teachers are encouraged to bring to blend the oftentimes theoretical science and technology methods taught in the classroom into their own teaching activities so that make students learn the most advanced methods of engineering practice in actual situations.

The education reform absorbs the CDIO concept and applies the theory into classes on the basis of the existing training model. More attention is given to carefully planning and setting up the unique conception, design, implementation, and project operation. The goals of the CDIO concept include sparking student interest in the engineering major and establishing a clear professional framework, which includes understanding the professional basic scientific knowledge, core engineering basic knowledge, basic knowledge of advanced engineering courses, and professional ethics and integrity for engineers. In addition, the CDIO teaching model can cultivate the students' practice ability and innovation. All projects in the CDIO teaching model need team cooperation. In 
the process of the project, students need to apply knowledge comprehensively and improve project organization ability, innovation, responsibility and so on [6].

\section{Implement of CDIO model in the course}

Using the Integrated Circuit Design course as an example, it is clear that the CDIO model is extremely beneficial for students. Designing circuits is a creative process where there are many possible solutions to the same one problem. Each designer has his own way of solving the problem while ensuring that all the requirements are met. The CDIO model is very suitable for courses such as Integrated Circuit Design, where students are given full play in creative thinking, and skills such as information organization, research, and teamwork are enhanced organically within the problem-solving framework. Students are encouraged to explore and experiment, as there is no one way to the correct solution.

Process of experiment for integrated circuit design course which is based on CDIO teaching concept design and execution make actual project requirements as the core and achieving project goals as the driving. All the students participated in the course are separated in two classes by their own willing. One is the regular class using traditional way to finish their experiments and the other one is comparison using CDIO model. In the CDIO model class, students study, discuss with each other and display their final results in groups. In CDIO experiment teaching classes, students are provided several actual engineering projects such as data converter and interface circuit in different application background. Students in CDIO model class are separated into 6 to 7 groups, with 5-7 students in each group. In order to guide the students to complete the experiment in a better way, course steering group is set up to provide counseling and guidance for the students, to assist students to choose those valuable resources and technical information, and to help them control the progress of the project.

Before the start of the experiment, course steering group posts actual engineering requirements of project and reference for each group. Students need to arrange their work, analysis the requirements, learn knowledge, discuss together about the scheme of project. In this model the teacher's role transform from "teacher" into "director". They encourage students to develop ideas, guide students to think and analysis in a critical way, inspire students' inner power to explore and acquire knowledge and make the whole team together to complete the project and achieve learning goals.

In specific, students organize and arrange task by themselves. Everyone in the group has his clear arrangement. They get new knowledge and information from books, journals, Internet and some other ways separately. Then members in a group discuss and exchange knowledge together. They need to analysis and design the structure of the circuits according to simulation results. Difficulties during the process call them work harder and closer to overcome. The most difference from traditional teaching model, in the whole process, is no "authority" exist. Students seek truths and ways to solve the problems equally. In this condition, the relationship among students is mutual cooperation, depending on each other, improving together instead of competing with each other. Students obtain more in CDIO learning process though they need to take more tasks and responsibilities.

At last, CDIO class use project report as the finals instead of traditional form. Each group shows their own achievements to teachers and all the students, such as circuit structure, principle of interpretation, specific details of approach, simulation results and so on. Teachers in course steering group and students in other groups review the results and give the scores of each project. It is a better way to mobilize students' participation and meet the students' sense of victory. At the same time, through contract between different groups, it can expand the thinking of students to solve the problem, find their own advantages and disadvantages, and prompt students to self-reflection.

This is a reform and exploration for experimental teaching. The final exam (written) result of CDIO class and regular class courses shows that average score of CDIO class is 77.68 and regular class is 73.73 in comparison. A questionnaire survey is conducted in the CDIO class and regular class at the same time. The results show that $91.9 \%$ of the students think that CDIO teaching methods can stimulate interest in learning and motivation; $89.71 \%$ of the students consider that CDIO model can improve the ability of comprehensive study; $93.55 \%$ of the students reflect that 
their knowledge is broader; $95.16 \%$ of the students think CDIO model is helpful to understand relevant knowledge and mastery. The result also shows that $75.33 \%$ of students in the regular class change their ideas and come round to participate in the CDIO model class.

\section{Issues in CDIO model teaching reform}

Students' learning habits. Students are pushed to change their learning habits in CDIO model. In traditional teaching model, they depend on teachers strongly with less active, which lead some students fail to understand the core content of the course totally or some deviation to understand. In the beginning, many students do not adapt it. They always hope that teacher is able to provide a full or half complete solution instead of search and exploration by themselves. For another, many students are lack of ability to hold whole process of project, although the teacher gives some suggests and notice about time node during process. However, there are still some students can't complete the task within the stipulated time node.

Students' participation. In the traditional experiment teaching, there is little difference between students' participation. But in CDIO model teaching base on project and teamwork which lead difference participation in the experiment among them. Students with high learning enthusiasm and strong learning ability are in high degree compare with lower ones. Even some give no contribution to the project. However, this conflict with the purpose of the CDIO model of teaching. An effective and scientific evaluation criteria system need to be set up to improve and assess participation and enable the student to finish their study on time.

Scientific and feasible evaluation standard. Standard is also one of the problems that need to be solved. In the traditional teaching model, almost every experiment has relatively unified criteria, but in CDIO model, it depends on the project and accomplishment. It is impossible to give an exact rule and standard because different project has different topic and content and contribution of each student to project is also different.

Suitable project. Project plays a very important role in CDIO teaching model. In abroad, projects in the courses are open and selected according to students' opinions. In China, it is exploring on the way. In this one, teachers provide several projects according their research and students' background before classes. And it is also allowed students choose the project which they are very interested in. In order to make projects implement in limited time, the projects provided by teachers are drew boundaries which conflict with the aim of this reform. In another situation, it is impossible to finish because projects are too difficult and complex, if the students have right to choose freely. So it needs further exploration and research about how to develop and meet the requirements of course.

\section{Solution of problems in CDIO model reform}

Mobilize students' learning passion. Passion and interest can lead students learning more and efficient. How to induce it? Many educators around the world provide their ways. In this exploration, teachers pay more attention about learning way and process of projects instead of knowledge. Such like fishing, they show students how to fish instead of fish, changing students' traditional learning habits. According to content and background of projects, teachers provide ways and directions to solve problems, instead of answers, during discussing with students. With the aim of finding answers to the practical questions, students start an "exploration", which can mobilize their learning enthusiasm fully. Study and exploration to solve practical problems in the course projects can increases students' learning achievement definitely. At the same time, it also can improve the students' initiative and obtain ways how to solve the problems, meeting the requirement of engineering education.

Team mutual evaluation. Team mutual evaluation provides a way to avoid students without any contribution to the team. The basic of CDIO model teaching reform is that project or product should be accomplished by all the team members. In order to make every student participate in it completely, "team mutual" component is introduced. Each student gets a score from other team members according to actual. The average of team mutual evaluation is a part of the final scores except the highest and lowest. Teachers and other teams also give scores to the team according their accomplishment. 
Students and teachers decide evaluation criterion. In this model, teachers and students discuss and make evaluation criterion together. In traditional teaching program, the grading rules are mainly set by the teacher, according to students' performance in the classes, homework, experiment, and examination. In this exploration, referring to other institutions from foreign and domestic, the criterion and details about all aspects of students' performance are discussed and represented by teachers and students together. In other words, students participate in evaluation and give scores. In this way, students feel that they are the main of the classes, not just participants, and it also prevents students from exploiting loopholes at the same time.

Project proposal. In the reform, the breadth and depth of project, as core of the course, affect the teaching effects and students' learning directly. The course steering group brainstorm with the students about almost all aspects of the project. So that project is suitable for the actual situation of the students, and meet the goals and requirements of course.

\section{Acknowledgements}

The exploration and application of CDIO teaching model in the course of integrated circuits, in general, have developed an important resource for engineering educators and curriculum developers [7]. The successful implement needs teachers to pay more attention and consider carefully about suitable project design, ways of guidance, details of process, students' background and knowledge level. It also needs establish an effective and timely interaction between teachers and students. Although there are some deficiencies in this reform, it is extremely worthy to research and explore further, even the possibility of combining it with other teaching methods to promote and improve practical education.

This paper was supported by "Beijing Higher Education Young Elite Teacher Project".

\section{References}

[1] A brief introduction about CDIO, CDIO China website: http://www.chinacdio.cn.

[2] Gang Wang. Reading and thinking over the CDIO engineering education mode [J]. China's higher education research. 2009 (05).

[3] Huan Lei, Weiyi Tang, Edward f. Crawley, cultivating innovative, multi-level, professional scientific and technological personnel, CDIO engineering education reform ideas and talent cultivation model [J]. Journal of higher engineering education research. 2009 (05).

[4] Li Man-li, With historical interpretation CDIO and its application [J]. Journal of tsinghua university education research, 2008 (10).

[5] Quanli Kang, Xiaohua Lu, guang-jing Xiong, CDIO outline and engineering innovative talents cultivation [J], journal of higher education research, 2008 (4).

[6]Joakim Wren and Johan Renner, Enhancing Student Engagement - A CDIO Approach in an Engineering Physics Master Program, International Symposium on Project Approaches in Engineering Education, 2011

[7]Young, P.W. et al., Design and Development of CDIO Student Workspaces - Lessons Learned. In Proceedings of the American Society for Engineering Education Annual Conference \& Exposition, American Society for Engineering Education, 2005 